\title{
Evaluation of the correlation between concentration of volatile organic compounds and temperature of the exhaust gases in motor vehicles
}

\author{
Maria Skrętowicz ${ }^{1}$, Radosław Wróbel ${ }^{1, *}$, and Monika Andrych-Zalewska ${ }^{1}$ \\ ${ }^{1}$ Wroclaw University of Science and Technology, Faculty of Mechanical Engineering, Braci \\ Gierymskich 164, 51-640 Wrocław
}

\begin{abstract}
Volatile organic compounds (VOCs) are the group of organic compounds which are one of the most important air pollutants. One of the main sources of VOCs are combustion processes including fuel combustion is internal combustion engines. Volatile organic compounds are very dangerous pollution, because even in very low concentrations they have significant harmful effect on human health. A lot of that compounds are mutagenic and carcinogenic, in addition they could cause asthma, intoxication or allergy. The measurements of VOCs are quite problematic, because it is required using the specialist analytical apparatus, ex. chromatograph. However, not always it is need to measure the content of that compounds in engine exhaust with high precision and sometimes it is enough only to estimate the level of the concentration. Emission of the VOCs mainly depends on the combustion process in the engine and this determines the temperature of the exhaust gases. In this paper authors tried to determine if the correlation between temperature of exhaust gases and VOCs' concentration exist and is able to determine.
\end{abstract}

\section{Introduction}

Motor vehicles, especially in big cities, are a very relevant source of the air pollution. Although producers are forced by law acts to produce low emission engines, the share of the internal combustion engines in the air pollution is still significant [1]. The most important vehicles category, in terms of the numerical amount, is passenger cars which are mostly driven by spark ignition engines [2]. The most harmful exhaust components are: carbon monoxide $(\mathrm{CO})$, carbon dioxide $\left(\mathrm{CO}_{2}\right)$, hydrocarbons $(\mathrm{HC})$, nitrogen oxides $\left(\mathrm{NO}_{\mathrm{x}}\right)$ and in trace amounts sulphur and lead compounds [2]. The main cause of the formation of hydrocarbons is the incomplete combustion which interrupts the chain of elementary reactions [4]. This situation is due to the local or global deficit of the oxygen and disturbances of the combustion process. Deficiency of the air in the combustion chamber could be caused not only by the combustion of rich air-fuel mixture, but also by

\footnotetext{
* Corresponding author: radoslaw.wrobel@pwr.edu.pl
} 
contamination of inlet air. Disruptions of the burning process are especially in cases of the ignition missing or wall and slotted effects [5]. In addition, the causes of the hydrocarbons emission are oil and fuel evaporation and oil burning in the combustion chamber. Emission of hydrocarbons is characteristic primary of spark ignition engines. Hydrocarbons are very hazardous and toxic for human health. The Euro 5 norm limits emission of hydrocarbons from passenger cars only for spark ignition engines and it is set to $100 \mathrm{mg} / \mathrm{km} \mathrm{[5].}$

One of the groups of hydrocarbons is volatile organic compounds (VOCs). Most of these compounds exhibit toxic effects on the human health, especially low boiling-point aromatic hydrocarbons or some of aldehydes. The most vulnerable are the cells of respiratory system, which is the main way of absorption of these compounds. Almost all of VOCs have a mutagenic and carcinogenic effect [7]. The most substantial air pollutants of this group are benzene, toluene, ethylbenzene and xylenes in all isomers. The group of these compounds is called briefly BTEX. This batch has also the most negative impact on the human health.

Nowadays, the measurement of the total hydrocarbons in the fumes is pretty easy and possible to take at most diagnostic stations (with FID analysers). However, in order to evaluate some specific components, such as BTEX, specialist and advanced equipment (e.g. gas chromatography) is required. It is obvious that the more the engine load increases, the more the temperature of the combustion process raises. As the temperature in the combustion chamber increases, the temperature of exhaust fumes at the cylinder outlet continues to rise. Simultaneously, when the temperature in the combustion chamber is higher, the fuel combustion process runs better (i.e. complete combustion). Thus, the higher the temperature is, the fewer hydrocarbons in the exhaust gases are. The aim of this study is to determine if it is possible to estimate the concentration of selected aromatic hydrocarbons (BTEX) in the exhaust based on the exhaust temperature measurement. Thanks to this analysis, it would be easy and quick to estimate the amount of emitted VOCs, excluding complicated analyses that require expensive equipment. The research focuses, among other things, on the measurement of VOCs in the exhaust fumes (determining emission factors), the influence of temperature on the VOCs inside the car cabin and the impact of ambient temperature on the VOCs content in exhaust [7-10].

\section{Materials and Methods}

The investigations were conducted on the spark-ignition engine Fiat 1.2 on the engine test bench in the Department of Automotive Engineering, Wroclaw University of Science and Technology. The tested engine had 4 cylinders and 12 valves and was equipped with three-way catalyst reactor (TWC). In the Figure 1 the test bench was shown. The test bench was also equipped with a drive shaft and the water-cooled electromagnetic brake EMX $100 / 10000$, which allowed applying the engine torque. 


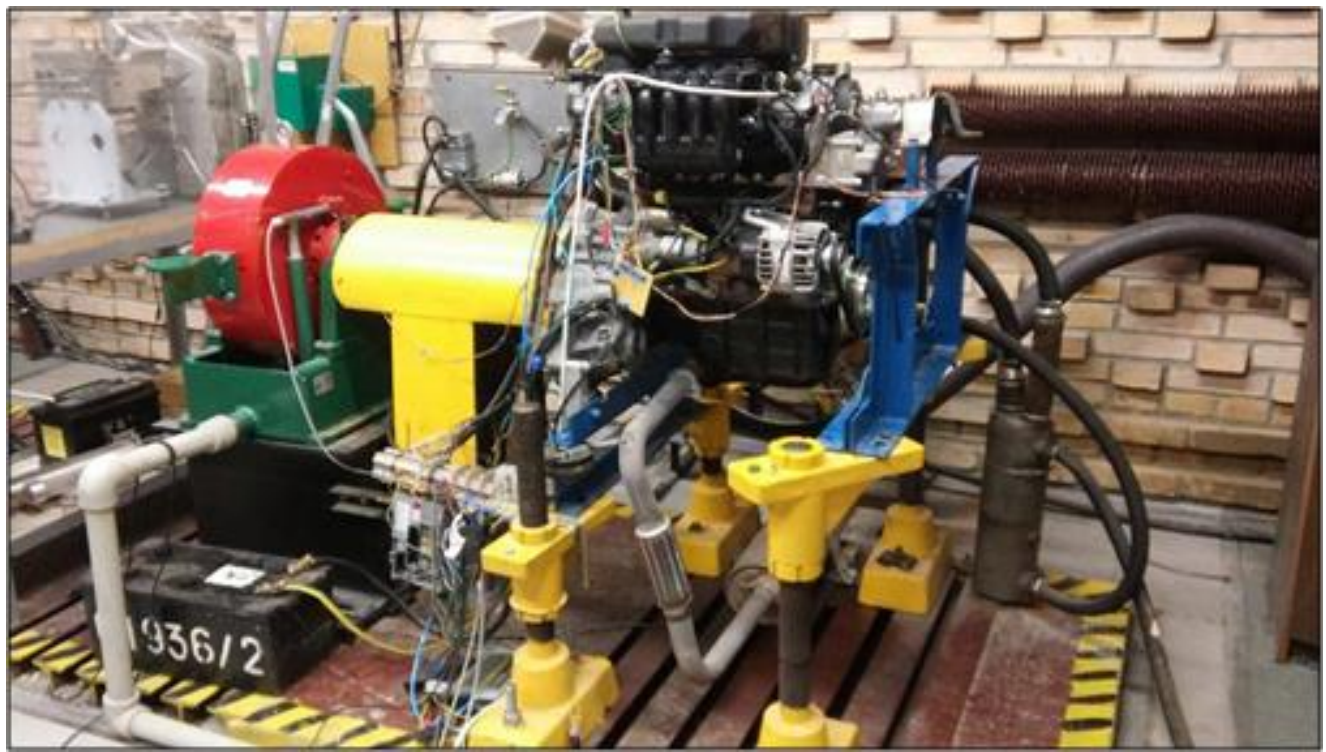

Fig 1. The engine test bench, Fiat 1.2

The engine was powered by the commercial gasoline with 95 octane number. Investigations began when the engine has reached its operating temperature. As it was already mentioned, the engine was cooperating with TWC, but the samples were taken only before the reactor (the investigation focused on the raw exhaust).

As it was written below the aim of this research was to evaluate the correlation between the temperature of exhaust fumes and the concentration of volatile organic compounds (VOCs) in them. The knowledge of the relationship between these two parameters could be helpful while estimating the level of the VOCs content in exhaust fumes without complicated chemical analysis of VOCs. These tests could answer the question if it is possible to get the mathematical equation of these parameters.

In the tests load characteristic of engine with fixed rotational speed $(2500 \mathrm{rpm})$ was performed. The engine was loaded with the electromagnetic break which was coupled to the engine with the torque values from $0 \mathrm{Nm}$ to $80 \mathrm{Nm}$, every $10 \mathrm{Nm}$. Changing the engine's torque with constant rotational speed in spark ignition engine, the temperature of the combustion process and thus the temperature of exhaust fumes changes as well. Moreover, the additional fuel consumption (in $\mathrm{g} / \mathrm{s}$ ) was measured.

The high temperature, pressure and other harsh environmental conditions distort the measurement method. In this case thermocouples appear which the best cluster of sensors is. It consists of a number of factors: the lack of need for the placements of contacts soldered or bonded in place of the measurement and a method for mounting the diagnostic element. In case of measurement with the use of semiconductor devices, the installation is more difficult (and hence expensive). Still, it is possible.

During the research, K-type thermocouples (NiCr-NiAl) were used [11]. Parameters of these elements could be used in the temperature's range between -40 to $1000{ }^{\circ} \mathrm{C}$. In this case, LimaTherm thermocouples were used (product no. PTTK-TKB-45-1-SO-150-4m-Si). This kind of sensors is equipped with compensatory wire which facilitates measurement. Thermocouples were placed on, in and out of catalyst (Figure 2). 


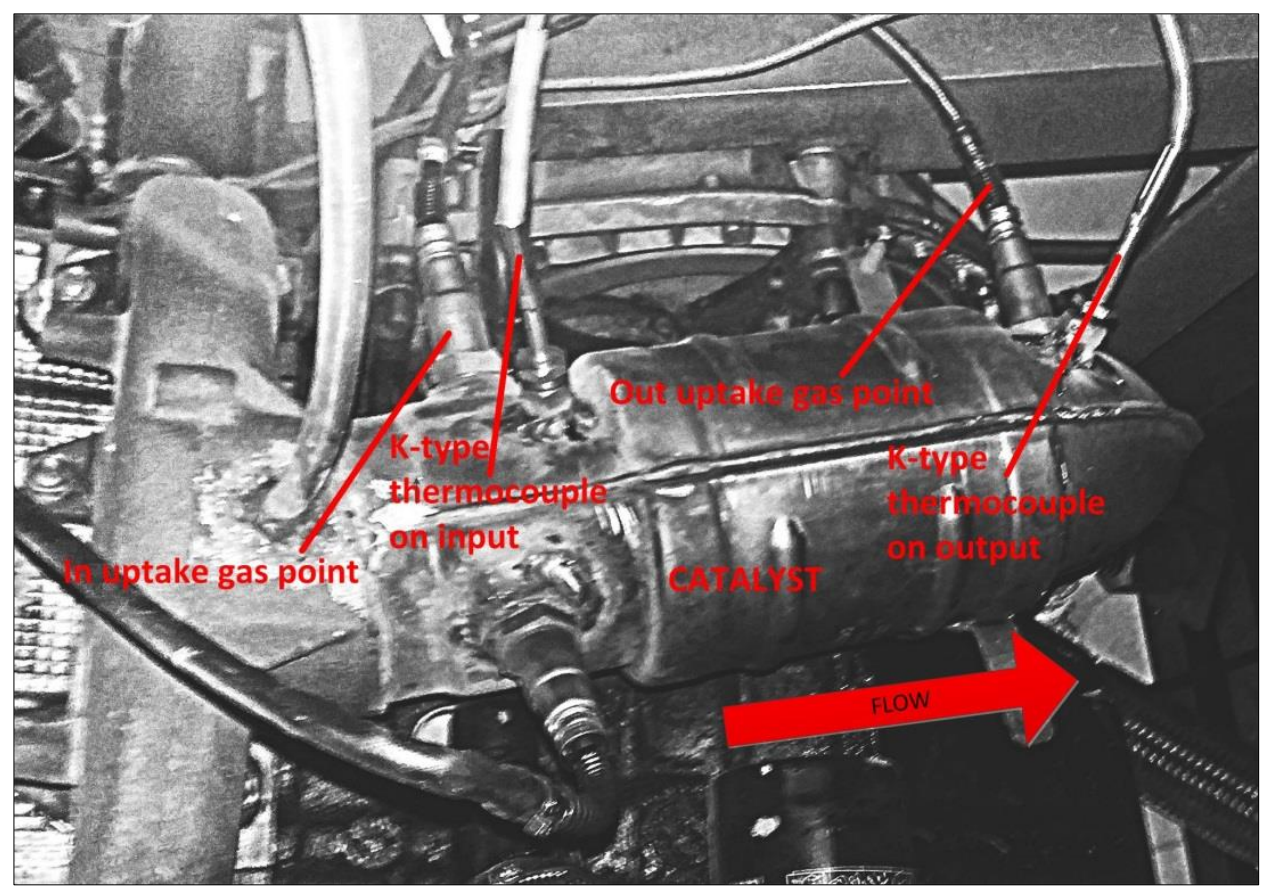

Fig. 2. The catalyst with thermocouples and gas uptake points

The acquisition system was based on the classic ADC card National Instrument (9215 type). Although this card is not directly designed for temperature measurements, the input voltage range allows performing tests. In a program written in LabView the object language corrective functions was applied. It permitted reading the temperature directly [12]. The measurements were performed at the same time, in order to synchronize the moment of sampling for toxic compounds and temperature.

During the tests, infrared camera was also selectively used so as to confirm the order of magnitude indicated by the thermocouple.

The samples of the fumes for chemical analysis of VOCs were taken from special connectors to Teflon bags by the vacuum pump. Then, the content of the bags was given by semi-automatic aspirator ASP-3II into special tubes filled with active carbon (Figure 3). The aspirator was equipped with the pomp and flow controller. From each bag $10 \mathrm{dm}^{3}$ of exhausts were transferred with a fixed airflow rate set at $30 \mathrm{dm}^{3} / \mathrm{h}$. All samples were moved to the Laboratory of Emission Researches in the Department of Automotive Engineering, Wroclaw University of Science and Technology, where were analysed with a gas chromatography (GC) method. The step preceding the chemical analysis was to prepare the samples by desorption VOCs from active carbon using the carbon disulfide $\left(\mathrm{CS}_{2}\right)$ as a solvent. Chromatographic analysis was carried out using a gas chromatograph Varian 450GC equipped with a flame ionization detector (FID), a capillary column and a system of automatic feeding of samples (autosampler). 


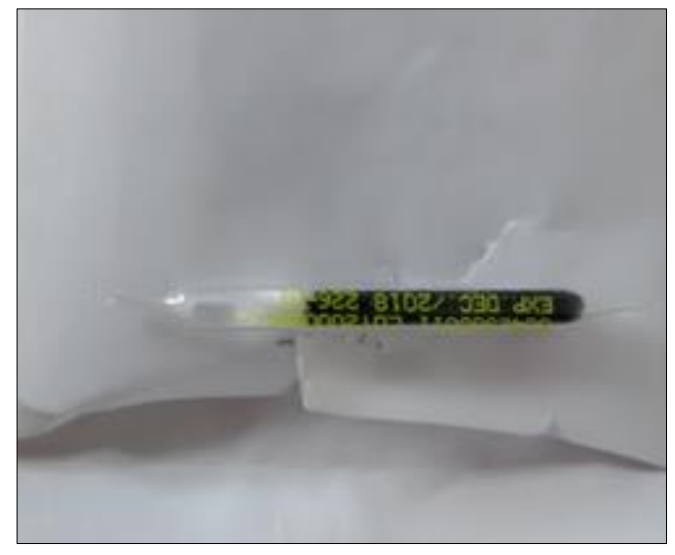

Fig. 3. The tube with active carbon

\section{Results}

As the results of measurements, VOCs' concentration and exhausts' temperature values before catalyst reactor was received for chosen points of engine's work (as load characteristic). The values received directly from the gas chromatography were obtained as concentrations of every identified VOCs in ppm (parts per million) in the used solvent $\left(\mathrm{CS}_{2}\right)$. It was necessary to calculate VOCs' concentrations in sampled fumes in $\mathrm{mg} / \mathrm{dm}^{3}$. Due to the fact that the most important (have been identified in the highest concentrations) and harmful for the human health compounds of VOCs group are benzene, toluene, ethylbenzene and xylenes (BTEX), these compounds were taken for the further consideration. In Table 1 all measurements and calculated results are presented.

Table 1. The concentration of analysed VOCs (in $\mu \mathrm{g} / \mathrm{m}^{3}$ ) and temperature values

\begin{tabular}{|c|c|c|c|c|c|c|}
\hline Torque, Nm & $\mathbf{T},{ }^{\mathbf{0}} \mathbf{C}$ & Benzene & Toluene & $\begin{array}{c}\text { Ethylbenzen } \\
\mathbf{e}\end{array}$ & $\begin{array}{c}\text { p-,m-,o- } \\
\text { xylene }\end{array}$ & $\begin{array}{c}\text { Sum of } \\
\text { BTEX }\end{array}$ \\
\hline 0 & 374 & 7.25 & 22.18 & 4.82 & 10.53 & 44.78 \\
\hline 10 & 399 & 5.21 & 15.35 & 3.66 & 8.01 & 32.22 \\
\hline 20 & 453 & 5.99 & 18.96 & 4.70 & 10.59 & 40.23 \\
\hline 30 & 482 & 1.14 & 4.18 & 0.69 & 3.01 & 9.01 \\
\hline 40 & 507 & 1.17 & 4.19 & 0.63 & 2.78 & 8.77 \\
\hline 50 & 533 & 1.21 & 4.36 & 0.73 & 3.02 & 9.32 \\
\hline 60 & 561 & 0.31 & 1.03 & 0.12 & 0.55 & 2.01 \\
\hline 70 & 577 & 1.17 & 3.95 & 0.55 & 2.37 & 8.03 \\
\hline 80 & 621 & 0.50 & 1.35 & 0.15 & 0.65 & 2.64 \\
\hline
\end{tabular}

As shown in Table 1, when the engine's load changes, the combustion temperature increases at constant speed (in this test $2500 \mathrm{rpm}$ ). Thus, exhaust fumes temperature raises as well. It is known that the combustion is closer to the complete one. Therefore, the hydrocarbon concentration decreases. The linear regression equations were used so as to evaluate the dependency of the VOCs and exhaust temperature. Statistical analyses were performed in Statistica StatSoft software. Every compound (benzene, toluene, ethylbenzene 
and p-, m-, o-xylene) was examined separately and the sum of BTEX was analyzed as well. While conducting the statistical analysis, the following parameters were taken into consideration:

absolute value of the correlation coefficient, $R$, coefficient of determination, $R^{2}$, which shows how the independent variable (here: the temperature) explains the dependent variable (here: the concentration of VOCs),

Beta, $\beta$, which is equal to the correlation value and shows the direction of the straight line,

constant term, $a$.

Based on the above parameters the linear regression equations have been determined. They show the quantitative relationship between analysed variables, i.e. the temperature and VOCs' concentration. The results of all calculations are presented in Table 2. As it is visible in the table, the coefficient of determination in every case exceeds 0.73 . It indicates a very good correlation between the analysed variables [13]. This means that on the basis of the exhaust's temperature, using the determined equations, the volatile organic compounds can be estimated with more than $70 \%$ of accuracy.

Table 2. Results of statistical analysis of linear regression

\begin{tabular}{|c|c|c|c|c|}
\hline $\begin{array}{c}\text { Type of the } \\
\text { compound }\end{array}$ & $\mathbf{R}^{\mathbf{2}}$ & $\boldsymbol{\beta}$ & $\mathbf{a}$ & Equation \\
\hline Benzene & 0,76 & $-0,8728$ & 16,9543 & $\mathrm{C}_{\mathrm{B}}=16,9543-0,0285 \cdot$ Temperature \\
\hline Toluene & 0,77 & $-0,8753$ & 51,6493 & $\mathrm{C}_{\mathrm{T}}=51,6493-0,0864 \cdot$ Temperature \\
\hline Ethylbenzene & 0,74 & $-0,8583$ & 12,2160 & $\mathrm{C}_{\mathrm{E}}=12,216-0,0208 \cdot$ Temperature \\
\hline $\begin{array}{c}\text { p-,m-,o- } \\
\text { xylene }\end{array}$ & 0,77 & $-0,8768$ & 26,0035 & $\mathrm{C}_{\mathrm{X}}=26,0035-0,0427 \cdot$ Temperature \\
\hline Sum of BTEX & 0,77 & $-0,8752$ & 106,8230 & $\mathrm{C}_{\mathrm{BTEX}}=106,823-0,1784 \cdot$ Temperature \\
\hline
\end{tabular}

\section{Summary and discussion}

The research of the engine operation has shown that it is possible to estimate the concentration levels of the analysed volatile system. However, it should be borne in mind that three-way catalysts are standard equipment in modern vehicles powered by sparkignition engines.

The analysis was carried out on one engine with fixed engine parameters (e.g. engine capacity, compression ratio) and performance parameters (e.g. torque, rotation speed, inlet airflow, etc.). The outcome of dependencies is true and can be only applied to this engine. In order to generalize the results of the research and to derive the universal (in terms of different types of spark ignition engines) dependencies, several additional aspects need to be considered in subsequent studies. One of the most important points in terms of the engine performance is the application of VOCs emission, despite their concentrations. It is very crucial with regard to the engine control and preparation of the air-fuel mixture. In spark-ignition engines without supercharging, when the engine load changes, the air flow in the intake manifold and the exhaust flow change as well.

In addition, the tests were conducted only in a certain operating range of the engine, at a constant rotational speed of $2500 \mathrm{rpm}$. Therefore, the obtained dependencies can be only applied for this speed. So as to estimate the VOC content at the full engine range, it is 
important to prepare and implement an experiment plan where various engine operating points (both load and rotation speed) are analysed. This study goes to show if it is possible to estimate VOCs content based only on exhaust temperatures, or whether an additional engine performance parameter such as rotation speed is required. However, it should be borne in mind that both of these parameters are much simpler to measure comparing to the measurement of volatile organic compounds.

Summing up, it is possible to obtain equations that describe the relationship between the exhaust temperature and the content of volatile organic compounds. The continuation of the research in this realm should focus on the following aspects:

examination of the dependencies over the engine's full operating range (evaluate whether additional parameters are required to obtain the analysed relationship), analysis of VOCs emissions instead of their concentrations (additional measurement of air flow in the intake manifold) - the universality of dependencies,

- testing more engines so as to generalize dependencies, consideration of a three-way catalyst which oxidizes volatile organic compounds (hydrocarbons) and thereby changes their content at the tail end of the exhaust pipe,

changing the place of experiment from the engine test stand (static testing) to performance testing of actual vehicles (e.g. on a chassis dynamometer).

\section{References}

1. Central Statistical Office, Transport. Activity results in 2015 (Warsaw 2016)

2. J. Merkisz, J. Pielecha, Emission of the particle matter from motorization (Wydawnictwo Politechniki Poznańskiej, Poznań 2014)

3. J. Merkisz, Ecological problems of internal combustion engines (Wydawnictwo Politechniki Poznańskiej, Poznań 1998)

4. Z. Chłopek, Environmental protection. Vehicles (Wydawnictwa Komunikacji i Łączności, Warsaw 2002)

5. J. Merkisz, The impact of motorization on environmental pollution (Wydawnictwo Politechniki Poznańskiej, Poznań, 1993)

6. Regulation (EC) No. 715/2007 of the European Parliament and of the Council, Type approval of motor vehicles with respect to emissions from light passenger and commercial vehicles (Euro 5 and Euro 6) and on access to vehicle repair and maintenance information (Brussels 2007)

7. A. Janicka, Toxicity assessment of the microatmosphere of the interior environment of a motor vehicle (Oficyna Wydawnicza Politechniki Wrocławskiej, Wrocław 2013)

8. J. Wang, L. Jin, J. Gao, J. Shi, Y. Zhao, Sh. Liu, T. Jin, Zh. Bai, Ch. Wu, Sci Total Environ, 110-1, 445-446 (2013)

9. K. Kim, J. Szulejko, H.J. Jo, M.H. Lee, Y.H. Kim, E. Kwon, Ch.J. Ma, P. Kumar, Environ Pollut, 215, 340-346 (2016)

10. A. Roy, Y. Choi, Atmos Environ, 152, 240-245 (2017)

11. L. Michalski, K. Eckersdorf, J. Kucharski, J. McGhee, Temperature Measurement (John Wiley \& Sons Ltd, 2002)

12. LabView website, http://poland.ni.com/labview

13. M. Korzyński, Methodology of experiment (Wydawnictwo WNT, Warsaw 2013) 